\title{
Community supported agriculture plus nutrition education improves skills, self- efficacy, and eating behaviors among low- income caregivers but not their children: a randomized controlled trial
}

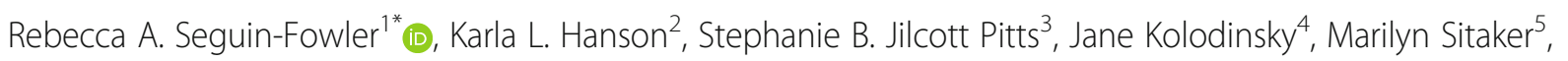
Alice S. Ammerman ${ }^{6}$, Grace A. Marshall ${ }^{7}$, Emily H. Belarmino ${ }^{8}$, Jennifer A. Garner ${ }^{9}$ and Weiwei Wang ${ }^{10}$

\begin{abstract}
Background: Adults and children in the U.S. consume inadequate quantities of fruit and vegetables (FV), in part, due to poor access among households with lower socioeconomic status. One approach to improving access to FV is community supported agriculture (CSA) in which households purchase a 'share' of local farm produce throughout the growing season. This study examined the effects of cost-offset (half-price) CSA plus tailored nutrition education for low-income households with children.

Methods: The Farm Fresh Foods for Healthy Kids (F3HK) randomized controlled trial in New York, North Carolina, Vermont, and Washington (2016-2018) assigned caregiver-child dyads $(n=305)$ into cost-offset CSA plus education intervention or control (delayed intervention) groups. Following one growing season of CSA participation, changes in children's diet quality, body mass index (BMI), and physical activity; caregivers' nutrition knowledge, attitudes, behaviors, and diet quality; and household food access and security were examined using multiple linear or logistic regression, with adjustment for baseline value within an intent-to-treat (ITT) framework in which missing data were multiply imputed.

Results: No significant net effects on children's dietary intake, BMI, or physical activity were observed. Statistically significant net improvements were observed after one growing season for caregivers' cooking attitudes, skills, and self-efficacy; FV intake and skin carotenoid levels; and household food security. Changes in attitudes and selfefficacy remained one-year after baseline, but improvements in caregiver diet and household food security did not. The number of weeks that participants picked up a CSA share (but not number of education sessions attended) was associated with improvements in caregiver FV intake and household food security.
\end{abstract}

\footnotetext{
* Correspondence: r.seguin-fowler@ag.tamu.edu

${ }^{1}$ Texas A\&M AgriLife Research, 600 John Kimbrough Boulevard, Suite 512, College Station, TX 77843, USA

Full list of author information is available at the end of the article
}

(c) The Author(s). 2021 Open Access This article is licensed under a Creative Commons Attribution 4.0 International License, which permits use, sharing, adaptation, distribution and reproduction in any medium or format, as long as you give appropriate credit to the original author(s) and the source, provide a link to the Creative Commons licence, and indicate if changes were made. The images or other third party material in this article are included in the article's Creative Commons licence, unless indicated otherwise in a credit line to the material. If material is not included in the article's Creative Commons licence and your intended use is not permitted by statutory regulation or exceeds the permitted use, you will need to obtain permission directly from the copyright holder. To view a copy of this licence, visit http://creativecommons.org/licenses/by/4.0/ The Creative Commons Public Domain Dedication waiver (http://creativecommons.org/publicdomain/zero/1.0/) applies to the data made available in this article, unless otherwise stated in a credit line to the data. 
Conclusions: Cost-offset CSA plus tailored nutrition education for low-income households improved important caregiver and household outcomes within just one season of participation; most notably, both self-reported and objectively measured caregiver FV intake and household food security improved. Households that picked up more shares also reported larger improvements. However, these changes were not maintained after the CSA season ended. These results suggest that cost-offset CSA is a viable approach to improving adult, but not child, FV intake and household food security for low-income families, but the seasonality of most CSAs may limit their potential to improve year-round dietary behavior and food security.

Trial registration: ClinicalTrials.gov. NCT02770196. Registered 5 April 2016. Retrospectively registered.

Keywords: Community supported agriculture, Cost-offset, Subsidized, Low income populations, Skin carotenoids, Food security, Attitudes, Fruit and vegetable eating behaviors

\section{Background}

Despite the benefits of adequate fruit and vegetable (FV) intake [1], most individuals in the U.S. do not eat recommended amounts [2], with lower intake among individuals with lower socioeconomic status $[3,4]$. Findings suggesting that greater FV access is related to higher intake underpin ongoing public health efforts to increase FV intake $[5,6]$. One strategy to reduce disparities in FV access and intake is to leverage direct-to-consumer marketing of fresh produce - such as community supported agriculture (CSA) - to reach more low-income households [7, 8].

In the traditional CSA model, members pay for a 'share' of a farm's produce upfront, and then have consistent access to fresh produce throughout the growing season. Most studies have shown the purchase of fullpriced CSA to be positively associated with FV intake: CSA members consumed more FV $[9,10]$, had greater increases in FV intake than non-members [11, 12], and ate more fruits and/or vegetables during the CSA season than before [13-16]. However, some studies did not observe a positive effect $[17,18]$ or had mixed results [1922]. Prior research has also found positive associations between CSA purchase and diet quality $[14,15,17,19$, $23]$ and healthy eating behaviors $[10,11,13,15,21,24$, 25]. For example, compared to non-members, CSA members reported eating more salads [10], homecooked meals [11], and family meals [21]; fewer processed snacks [10]; and eating in restaurants less often [21]. CSA participation also may have implications for body mass index (BMI); one study showed a beneficial association between CSA and BMI [23] and another showed none [21].

Among the studies that examined associations between purchase of full-priced CSA and FV intake, diet quality, and healthy eating behaviors, some had small samples (e.g. 50 or fewer participants) [14, 18, 20], did not use a comparison group [13-20, 24, 25], and/or included only data from during or after the CSA season (i.e. no baseline or pre-test) $[9,13,15,16,23-25]$.
Further, none randomized participants to CSA or examined objectively-assessed FV intake and, as such, intervention-related bias may have influenced results. Two studies of CSA purchasers focused on low-income families $[15,22]$, but most included primarily middleand upper-income participants.

A persistent critique of the CSA model is that payment is generally required in advance of the growing season, which may limit participation by low-income families [26, 27]. CSA that provides a cost-offset to lowincome households (CO-CSA) removes this financial barrier by subsidizing a portion of the share price, eliminating up-front payments, and offering flexible payment plans. Descriptive studies have suggested that CO-CSA participation may positively impact $\mathrm{FV}$ access [28, 29] and intake [30,31]. A pilot study reported that all COCSA participants increased the variety of vegetables consumed, learned new ways to prepare vegetables, and liked a new vegetable after CSA participation, but there were no changes in other outcomes [29]. Longitudinal studies of cost-offset (or free) CSA programs more often reported increases in fruit and/or vegetable intake [32$36]$ than reported no changes $[29,37]$. A recent randomized trial comparing CO-CSA with unconditional cash transfer reported improvements in overall diet quality; diet quality subscores for total vegetables, total fruit, whole fruit, and empty calories; and food security status [36].

Similar to studies of full-priced CSAs, many studies of CO-CSA had small samples [27, 29, 31, 37], no comparison group [27, 29, 31, 34, 37], included only data from during/after the CSA season [30, 31, 33], and/or recruited samples not limited to low-income participants $[33,34]$. Only two studies used a randomized study design [36, 37] and none examined effect based upon objectively-assessed FV intake. Three of the CO-CSA programs provided $\mathrm{FV}$ at no cost to the participants [27, $32,37]$, and one provided home-delivered shares [32], both of which may limit their generalizability. Only two 
studies incorporated nutrition education for participants beyond general CSA tip sheets or newsletters [35, 37].

This study aims to fill gaps in the understanding of the effects of CO-CSAs on food security, dietary intake, and related outcomes. The overall aim of the Farm Fresh Foods for Healthy Kids (F3HK) randomized controlled trial was to assess the effect of CO-CSA participation coupled with tailored nutrition education for lowincome families with children living in rural and micropolitan communities [38]. The primary aim of this trial report is to assess the short-term net effect of CO-CSA plus nutrition education on children's diet quality, particularly FV intake. Secondary aims are to examine net effects of CO-CSA plus nutrition education on children's BMI, physical activity, and sedentary behavior, as well as on caregivers' food and nutrition skills, knowledge, attitudes, beliefs, and diet quality, as well as household food security. Tertiary aims are to test whether any observed short-term effects were durable after the CSA season ended (i.e. lasted into the next spring), and to estimate the role of intervention dose in understanding observed intervention effects.

\section{Methods \\ Intervention}

Development of the F3HK intervention was informed by formative interviews conducted with caregivers and children from low-income households in target communities [39, 40], CSA members and farmers [41], and cooperative extension nutrition educators [42], as well as analysis of observational data [30,31]. The focus of the F3HK intervention was a summer CSA membership of $15-24$ weeks length (mean $=21$ weeks) plus nutrition education [43]. Nine farms offered multiple CSA share sizes from which caregivers could select the option that best suited their needs and preferences (mean $=7.5$ items/week) [43]. Shares were offered at half-price and caregivers paid weekly, on average $\$ 13$, with money or Supplemental Nutrition Assistance Program (SNAP) benefits throughout the season [43]; research funds paid the other half of the price to the farm before the CSA summer season began. SNAP benefits are provided by the U.S. federal government to eligible low-income individuals and families (household income at or below $130 \%$ of the poverty line and a maximum of $\$ 2250$ in financial assets) [44]. The average monthly benefit per person in 2018 was $\$ 124.50$ [45]. If paying with their monthly SNAP benefits, families were choosing to use their SNAP funds to pay for the CSA share instead of any type of food from other authorized venues (e.g. grocery stores). Fidelity of the CSA was high with respect to produce quality and pick-up site functionality as observed and recorded by local research coordinators [43].
Participation level was high; on average, caregivers picked up their CSA share 88\% of weeks enrolled [43].

Families in the CO-CSA plus nutrition education group were offered kitchen tools and education classes. Caregivers selected 2-4 larger kitchen tools from among the following: food processor, crockpot, stockpot, large cutting board, chef's knife, salad spinner, and reusable grocery bag. Selected items were shipped to their home at the beginning of the CSA season [38]. Adults and children also were invited, but not required, to attend nine in-person CSA-tailored education classes offered locally [38]. Social Cognitive Theory [46], the Dietary Guidelines for Americans [47], the Physical Activity Guidelines for Americans [48], and agricultural calendars in each state [49-54] guided the design of the COCSA tailored curriculum [38]. Classes featured seasonal produce via food tasting, demonstrations, hands-on cooking activities, handouts, and recipes; two of the lessons involved field-based learning via grocery store and farm tours; and three lessons taught the use of a vegetable peeler, vegetable scrub brush, or paring knife which participants were allowed to keep [38]. Adherence to the curriculum was high as reported by educators and as observed and recorded by state research coordinators [43]. Most caregivers (77\%) and children (54\%) attended at least one class, but almost no one attended all classes [43].

\section{Study design}

The F3HK study (protocol published elsewhere [38]) used a randomized controlled trial with one-way crossover of control to intervention after 1 year. Participants enrolled in wave one (2016) were assigned to a two-year CO-CSA plus nutrition education intervention and in wave two (2017) were assigned to a one-year CO-CSA plus nutrition education intervention. One-to-one random assignment occurred following baseline assessments and was generated by Qualtrics in blocks of four within each of the 12 farm communities in New York, North Carolina, Vermont, and Washington. Multiple staff members reported assignments to participants, thereby reducing the likelihood of assignment prediction by study staff. Once assigned, neither participants nor staff were blinded to assignment for logistical reasons. Our study was approved by the University of Vermont (protocol ID: CHRBSS 16-393) and Cornell University (protocol ID: 1501005266) Institutional Review Boards.

\section{Sample}

Flyers, newspapers, and social media were used to advertise the study opportunity, and study staff directly recruited at schools, churches, libraries, community service organizations, and at local events from January through June 2016 and 2017. Participants were also 
identified via "word of mouth." Caregivers completed a brief electronic screening tool on a tablet or were later screened over the telephone. Households were eligible if they resided in a participating community, included a child aged 2-12 years old who was willing to participate, met guidelines for low income $(\leq 185 \%$ federal poverty level), and had not participated in CSA for at least 3 years [38]. This last criteria was included because we wanted to recruit participants who were 'naïve' to CSA programs. A total of 685 caregivers were screened for eligibility and $542(79.1 \%)$ were determined to be eligible; see Fig. 1.

Once determined eligible, caregivers had to agree to spend their own money or SNAP benefits on weekly CSA payments and complete the baseline survey, and an age-eligible child had to be willing to participate as well.
Of 542 eligible caregiver-child dyads, 305 (56.3\%) enrolled. The first dyad was enrolled on March 4, 2016 and the last on June 20, 2017. The target sample size of 300 was designed to detect a difference of one-third serving of vegetables between groups (power $=0.80, p=$ 0.05 , two-sided test), a targeted effect size slightly smaller than those reported in a systematic review of the effect of nutrition education on FV intake among lowincome adults [55].

\section{Data collection}

Data collection included online surveys that were completed by caregivers with input from children for children's diet measures, as well as physical measurements of skin carotenoids and children's height and body weight, which were obtained by research staff. Caregivers

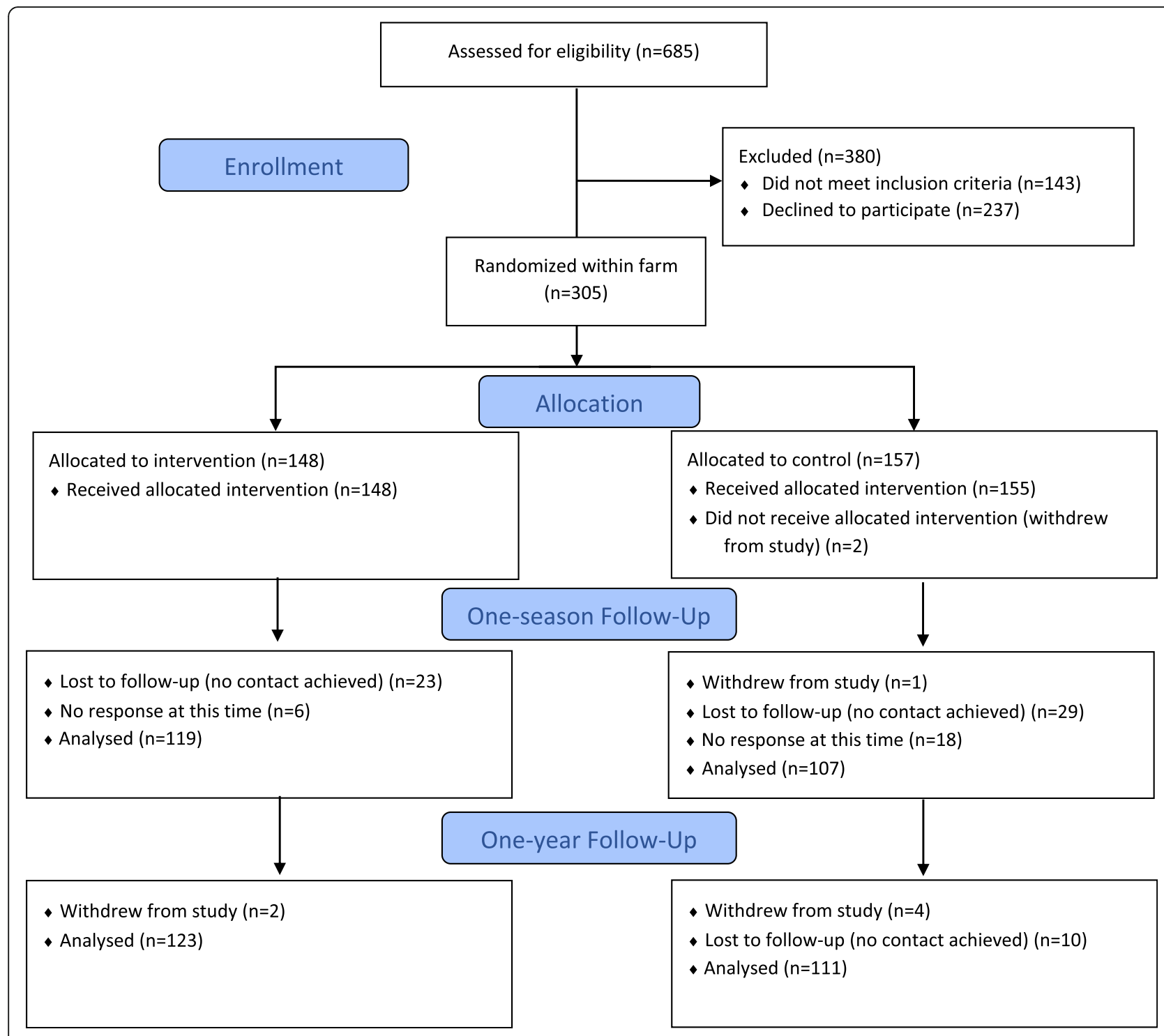

Fig. 1 Consolidated Standards of Reporting Trials Statement diagram showing study flow for Farm Fresh Foods for Healthy Kids (F3HK) 
also completed three 24-h recalls for, or with, their child. Because 24-h recalls can be time consuming, we expected fewer recall responses, presented this activity as optional, and provided separate compensation specifically tied to this activity completion. Data analyzed here were collected at baseline (spring), one-season follow-up (fall; mean $=+5.02$ months, $\mathrm{SD}=0.77$ ) and survey data only at one-year follow-up (spring; mean $=+9.69$ months, $\mathrm{SD}=0.81)$. Caregiver compensation included: $\$ 25$ for each online survey completed, \$50 each time three 24-h recalls were completed, and $\$ 10$ for skin carotenoid measures. Caregivers who completed surveys at all three time points also earned a $\$ 25$ bonus. Children were compensated $\$ 10$ for skin scanning and $\$ 10$ for height and weight measurements. Most participants (76.7\%) were retained through one-year follow-up measures.

\section{Primary outcomes}

Primary outcomes of children's dietary intake were measured using validated tools: online survey measures of FV intake and frequency of intake of sweets, salty snacks, and sugar sweetened beverages (SSBs); physical measurement of skin carotenoids; and online completion of 24-h dietary recall data for children. Survey items were completed by the caregiver with $70.0 \%$ of children age six or older assisting. FV intake with and without juice (cups/day) was measured using the National Cancer Institute's (NCI) All-Day Fruit and Vegetable Screener (FVS) [56]. Sweets, salty snacks, and SSB consumption were measured using the Beverage and Snack Questionnaire, version 2 (BSQ2) $[57,58]$. The BSQ2 was adapted to remove questions regarding FV and 100\% juice intake to avoid overlap with the FVS, and to omit distinctions in response options for consumption that occurred in-school and out-of-school. Monthly intake frequency of five items of candy, sweet baked goods, and ice cream were summed into "sweets"; three salty snacks items into "salty snacks"; and six items including regular sodas, sweetened coffee/tea and drinks, and flavored milks into "SSBs."

Caregivers completed two or three online dietary recalls for, or with, the child through the NCI Automated Self-Administered 24-h recall system [59]. At baseline, $10.6 \%$ of those who completed dietary recalls completed only two recalls and at one-season follow up 3.2\% only completed two recalls. Recalls provided additional measures of the child's FV intake with and without juice (cups/day), as well as solid fat (g), sodium (mg), and added sugar (tsp) intake. From 24-h recall data, the child's overall diet quality was assessed by the total Healthy Eating Index-2015 (HEI) [60, 61], and mean total energy intake as a percentage of child's estimated energy requirements (EER) given sex, age, and reported days of physical activity (described below) [47].

Skin carotenoids were assessed in-person with the Pharmanex@ Biophotonic Scanner S3 (NuSkin Enterprises, Provo, UT, USA) via resonance Raman spectroscopy (RRS) by trained research staff. Assessment of skin carotenoid score using RRS is a valid method to approximate FV intake in children [62-64] and is sensitive to increases in FV intake among youth [65]. The mean of two or three RRS measurements were used as an objective biomarker of children's FV intake.

\section{Secondary outcomes}

Secondary outcomes included child's body weight and activity levels; caregiver's skills, knowledge, attitudes, behaviors, and dietary intake; and household food security. Trained research staff measured the height and weight [66] of each child from which we calculated BMI percentile [67]. Each child's physical activity was reported by caregivers as days of physical activity $(\geq 60 \mathrm{~min})$ in the past week [68]. Sedentary activity was reported as hours per school day the child spent watching TV and hours per school day spent playing video games [68].

Caregivers' ability to select, store, and prepare CSA produce was measured using the 14-item Cooking Techniques and Meal Preparation Self-efficacy Scale (range 1 to 5) [69]. Seven additional questions about specific skills included in the F3HK curriculum were added to create an expanded 21-item scale [38]. Caregivers' ability to substitute FV for energy-dense foods was assessed using questions about monthly frequency of preparing nine different FV snacks for children, which were highlighted in the F3HK curriculum [38]. Responses were summed to create measures of the monthly frequency of preparing fruit, vegetable, and total FV snacks. Data also were collected to measure caregivers' ability to prepare foods to minimize added solid fat and sugar but were not analyzed due to low response.

Caregivers' knowledge, attitudes, and beliefs (KAB) about FV were collected via the online survey. Knowledge of FV recommendations was assessed with ordinal response options subsequently combined into indicators of $\geq 5$ cups FV or less, and FV covering half or more of a dinner plate or less. The four-item Negative Cooking Attitude Scale [69] was used to measure caregivers' attitudes towards cooking (range 1 to 5); higher scores indicate greater dislike of cooking. The 11-item General Nutrition Knowledge Belief Score collected beliefs about the importance of a healthy diet and other eating behaviors (range 1 to 4) [70]. Self-efficacy was collected via the 4-item Self-Efficacy for Eating/Cooking Fruits and Vegetables Scale (range 1 to 5) [69].

Caregiver's diet was assessed via the survey using the NCI-FVS and BSQ2 as described above. Skin 
carotenoids were measured for caregivers using RRS technology, which has been validated in adults [71-74] and responds to a high-carotenoid diet [75]. Home FV availability and accessibility were assessed using multiitem scales (range 1 to 4) [76]. Affordability and physical accessibility of FV were each assessed using one Likerttype question (range 1 to 5). Household food security was measured using the 6-item Short Form of the US Department of Agriculture Food Security Survey Module [77]. Households were classified as food secure if they experienced none or one of the indicators of insufficiency in the past 30 days.

\section{Participation level}

Participation level was measured as the number of weeks that participants picked-up the CSA share based on logs kept by farm staff, and as the number of CSA-tailored classes attended by the caregiver based on attendance logs kept by the educators. At both follow-up time points, caregivers reported whether or not they participated in a CSA outside of the intervention (e.g. a winter CSA), which was explored as a potential source of bias.

\section{Analyses}

Normality of continuous outcomes was checked by examining histograms and checking skewness and kurtosis statistics. Single time-point measures with skewness $>1.0$ were transformed to approximate normality (e.g. Ln FV intake; cube-root sweets, salty snacks, and SSBs; Ln added sugar; square-root solid fat; cube-root sodium; Ln sedentary hours; Ln FV snack preparation frequency). Baseline (spring) data were available for almost all participants for almost all variables: only $1.6 \%$ of data were missing for any of the survey outcomes. Skin carotenoid status was missing for $13.8 \%$ of participants at baseline, largely due to unforeseeable delays in the shipping of equipment. As expected, fewer participants $(80.7 \%)$ provided at least two 24-h recalls at baseline.

Follow-up (fall) data were available for the majority of participants. Fifty-five participants (18.0\%) withdrew or were lost to follow-up and another 24 (7.9\%) did not provide data at that time but were responsive later in the study. The primary concern was that data may not be missing at random (MAR) and, in the context of a health behavior intervention trial, that participants with worse baseline health behaviors might be most likely to drop-out or not report. To explore this potential bias, we compared baseline values for all outcomes for respondents and nonrespondents at one-season (fall) follow-up. For eight of 38 outcomes $(21.1 \%)$, cases missing follow-up data were significantly different from those not missing data, but there was no consistent direction to the associations -- missing follow-up data was associated with two healthier behaviors and six less healthy behaviors at baseline, and unrelated for the other 30 outcomes. These findings do not provide strong evidence that systematic bias resulted from missing data.

Multiple imputation was used because it is the most accurate approach to estimating missing data and standard errors that account for both variability due to sampling and to imputation itself [78]. Imputations followed standardized, rigorous procedures [79], included auxiliary variables [80], used $30 \mathrm{impu}-$ tations [78], and employed both standard and hierarchical approaches. Baseline and one-season followup data were imputed using a fully conditional specification (FCS) standard approach, which is considered an unbiased and robust approach to imputation of missing dichotomous and continuous data [81]. Logistic and linear regression were used for categorical and continuous variables, respectively [PROC MI, SAS software (SAS Institute Inc., Cary, NC, USA; version 9.4)]. Due to computational limitations, data were multiply imputed in four groups: 1) survey measures of diet and physical activity for children and caregivers; 2) survey measures of caregivers' $K A B$ and behaviors, and household food access, availability, and security; 3) objective measures with survey measures of diet and physical activity as additional auxiliary variables; and 4) outcome measures derived from 24-h recalls, also with survey measures of diet and physical activity as auxiliary variables. Participants who never provided any $24-\mathrm{h}$ recalls $(n=59,19.3 \%)$ were excluded from imputation and analysis of these outcomes. All models also included key characteristics as auxiliary variables [78]: random assignment group, state; caregiver race (white or not), age, education (college degree or not), and health status; and age, sex, and health of the child. Data for the three time points were similarly imputed using a FCS linear mixed-effects latent normal approach, which performs well for the estimation of regression model parameters in longitudinal data [78] and Blimp version 2 [82].

Analysis of change scores from baseline was the primary method of net effect estimation for continuous outcomes given high correlation between baseline and follow-up outcomes [83]. Changes in continuous outcomes were confirmed to approximate normality based on a skewness statistic under 2.0, or visual examination of residuals against the predicted means to confirm symmetry and even distribution. Change scores could not be calculated for binary outcomes and were modeled as the observed value at the time-point of interest. Regression estimates were considered significant at $p<0.05$. 


\section{One-season effects}

Estimates of changes from baseline (spring) to oneseason follow-up (fall) for intervention group relative to control were examined for all complete cases ( $\mathrm{n}$ varies) using multiple linear or logistic regression (for continuous and binomial variables, respectively), with adjustment for baseline value. These net one-season effects also were estimated using an intent-to-treat (ITT) framework, multiply imputed data $(n=305$ survey and objective measures, and $n=26424-\mathrm{h}$ recalls), and PROC MIANALYZE in SAS.

\section{Durability and participation level}

Net effects from baseline (spring) through one-year follow-up (spring) were examined similarly using multiply imputed longitudinal data and multi-level linear or logistic regression. An interaction between intervention and season (spring vs. fall) was included in models to test for differences in the intervention net effect at oneseason compared to one-year follow-up. Number of weeks of CSA pick-up and number of lessons attended were used to predict short-term change in outcomes within the intervention group.

\section{Sensitivity analyses}

The ITT analysis to assess one-year net intervention effect was conducted two more times to control for potential bias due to enrollment in a CSA outside the intervention: once assuming that the 77 missing responses got an outside CSA and once assuming they did not.

\section{Results}

Table 1 presents baseline characteristics of caregivers, children, and households. Overall, there were no notable differences in baseline characteristics across random assignment groups.

Complete case analysis revealed improvement in children's FV intake without juice as measured by $24-\mathrm{h}$ recalls $(+0.35$ cups/day, $p<0.05)$ (Supplemental Table 1 , Additional File 1). In the ITT analyses with multiply imputed data, no significant net effects on children's dietary intake remained (Table 2). Likewise, no net effects of F3HK participation were observed on the secondary outcomes of children's BMI, physical activity, or sedentary time in ITT analyses.

There were, however, significant one-season changes observed among secondary outcomes related to caregivers and households in both complete case and ITT analyses. All five measures of caregivers' skills improved significantly by the end of the summer CSA season. Both of the scales measuring cooking techniques and meal preparation self-efficacy improved in the intervention group relative to control $(+0.20, p<0.01$ [14-item scale] and $+0.29, p<0.001$ [21-item scale]). There were also statistically significant positive net effects on caregiver behaviors such as preparing FV as snacks for children $(+19.22, p<0.01)$, as well as preparation of fruit $(+7.92$, $p<0.01)$ and vegetables alone $(+12.09, p<0.05)$. F3HK showed no net effect on caregivers' knowledge of FV recommendations and general nutrition, but negative cooking attitudes $(-0.35, p<0.001)$ and self-efficacy for eating and cooking FV $(+0.38, p<0.001)$ improved. Caregivers' FV intake also improved in the F3HK intervention group relative to control, assessed by selfreported FV intake with and without juice $(+1.10, p<$ 0.05 and $+1.01, p<0.05$ ), and supported by net effects on objective measures of skin carotenoids $(+3312.16$, $p<0.05$ ). There were no observed effects on caregivers' consumption of sweets, salty snacks, or SSBs.

We also observed a positive one-season net effect of F3HK on two of the four measures of FV availability and access: the availability of FV in the home $(+0.11, p<$ $0.05)$ and ease of access to FV $(+0.23, p<0.05)$. Additionally, household food security (OR 1.67, $p<0.01$ ) showed net improvement.

Some one-season net effects on secondary outcomes were maintained into the following spring (when no CSA FV were being received; Table 3). Net one-season intervention effects were maintained at one-year followup for scales of cooking techniques and meal preparation self-efficacy $(+0.28<p<0.01$ and $+0.34, p<0.01)$, as well as negative cooking attitudes $(-0.25, p<0.01)$ and self-efficacy for eating and cooking FV $(+0.33, p<$ 0.01 ). One-year net intervention effects were not observed for self-reported or objective measure of caregivers' FV intake. One net effect on the householdavailability of $\mathrm{FV}$ in the home $(+0.15, p<0.01)$-was maintained, but the positive net effect on household food security did not continue into the spring (OR 1.27, $p=0.133)$. At one-year follow-up, 29 caregivers (9.5\%) reported purchasing a winter CSA; both sensitivity analyses to explore this source of potential bias produced results consistent with the tabled data.

Within the intervention group, the number of weeks that the CSA share was picked-up was associated with three positive one-season changes: one additional week of CSA share pick-up was associated with a decrease in child's salty snack intake $(-0.60, p<0.05)$ and an increase in adult's FV intake without juice $(+0.12, p<0.01$; Table 4). In addition, one additional week of CSA pick up was associated with improved household food security (+ 0.09 Ln odds, $p<0.05$ ); for example, households that picked up their share 21 weeks (75th percentile) were 3.73 times as likely to be food secure as households that picked up only 7 weeks (25th percentile). An increase in number of lessons attended was associated with short-term reduction in accessibility of $\mathrm{FV}$ in the home $(-0.03, p<0.05)$. 
Table 1 Baseline characteristics of enrollees in the F3HK intervention trial in four U.S. states, 2016-2017

\begin{tabular}{|c|c|c|c|c|c|c|c|}
\hline & & \multicolumn{3}{|c|}{ Intervention } & \multicolumn{3}{|c|}{ Control } \\
\hline & & $\mathrm{n}$ & Count (Mean) & $\begin{array}{l}\% \\
\text { (SD) }\end{array}$ & $\mathrm{n}$ & Count (Mean) & $\begin{array}{l}\% \\
\text { (SD) }\end{array}$ \\
\hline \multicolumn{8}{|c|}{ CAREGIVER CHARACTERISTICS } \\
\hline Age & & 148 & $(35.7)$ & $(7.5)$ & 157 & $(36.5)$ & $(8.4)$ \\
\hline \multirow[t]{2}{*}{ Sex } & Male & 148 & 5 & 3.4 & 157 & 3 & 1.9 \\
\hline & Female & & 143 & 96.6 & & 154 & 98.1 \\
\hline \multirow[t]{3}{*}{ General health } & Excellent - very good & 148 & 51 & 34.5 & 157 & 54 & 34.4 \\
\hline & Good & & 69 & 46.6 & & 57 & 36.3 \\
\hline & Fair - poor & & 28 & 18.9 & & 46 & 29.3 \\
\hline \multirow[t]{4}{*}{ Marital status } & Married & 148 & 63 & 42.6 & 157 & 69 & 43.9 \\
\hline & Separated, divorced, or widowed & & 42 & 28.4 & & 34 & 21.7 \\
\hline & Never married & & 31 & 20.9 & & 37 & 23.6 \\
\hline & A member of an unmarried couple & & 12 & 8.1 & & 17 & 10.8 \\
\hline \multirow[t]{5}{*}{ Highest year of school } & High school or less & 148 & 24 & 16.2 & 157 & 36 & 22.9 \\
\hline & Technical or vocational school & & 7 & 4.7 & & 7 & 4.5 \\
\hline & Some college & & 41 & 27.7 & & 41 & 26.1 \\
\hline & College graduate & & 56 & 37.8 & & 61 & 38.9 \\
\hline & Graduate or professional degree & & 20 & 13.5 & & 12 & 7.6 \\
\hline \multirow[t]{4}{*}{ Employment status } & Employed & 148 & 69 & 46.6 & 157 & 71 & 45.2 \\
\hline & Out of work & & 15 & 10.1 & & 22 & 14.0 \\
\hline & A homemaker & & 55 & 37.2 & & 53 & 33.8 \\
\hline & Student/retired & & 9 & 6.1 & & 11 & 7.0 \\
\hline \multirow[t]{6}{*}{ Race } & $\begin{array}{l}\text { American Indian/ } \\
\text { Alaskan Native }\end{array}$ & 148 & 1 & 0.7 & 157 & 3 & 1.9 \\
\hline & Asian/Pacific Islander & & 2 & 1.4 & & 2 & 1.3 \\
\hline & Black & & 23 & 15.5 & & 19 & 12.1 \\
\hline & White & & 112 & 75.7 & & 120 & 76.4 \\
\hline & Multiracial & & 7 & 4.7 & & 9 & 5.7 \\
\hline & Not one of the above & & 3 & 2.0 & & 4 & 2.5 \\
\hline \multirow[t]{2}{*}{ Hispanic } & Yes & 148 & 9 & 6.1 & 157 & 10 & 6.4 \\
\hline & No & & 139 & 93.9 & & 147 & 93.6 \\
\hline \multicolumn{8}{|l|}{ CHILD CHARACTERISTICS } \\
\hline Age & & 148 & $(6.1)$ & $(3.0)$ & 157 & $(6.2)$ & (3.0) \\
\hline \multirow[t]{2}{*}{ Gender } & Male & 148 & 65 & 43.9 & 157 & 81 & 51.6 \\
\hline & Female & & 83 & 56.1 & & 76 & 48.4 \\
\hline \multirow[t]{3}{*}{ General health } & Excellent - very good & 148 & 119 & 80.4 & 157 & 124 & 79.0 \\
\hline & Good & & 23 & 15.5 & & 25 & 15.9 \\
\hline & Fair - poor & & 6 & 4.1 & & 8 & 5.1 \\
\hline \multicolumn{8}{|c|}{ HOUSEHOLD CHARACTERISTICS } \\
\hline \multirow[t]{4}{*}{ State } & New York & 148 & 45 & 30.4 & 157 & 48 & 30.6 \\
\hline & North Carolina & & 37 & 25.0 & & 40 & 25.5 \\
\hline & Vermont & & 34 & 23.0 & & 37 & 23.6 \\
\hline & Washington & & 32 & 21.6 & & 32 & 20.4 \\
\hline \multirow[t]{3}{*}{ \# Adults in household } & 1 adult & 148 & 48 & 32.4 & 157 & 54 & 34.4 \\
\hline & 2 adults & & 87 & 58.8 & & 85 & 54.1 \\
\hline & 3 or more adults & & 13 & 8.8 & & 18 & 11.5 \\
\hline \multirow[t]{2}{*}{ \# Children in household } & 1 child & 148 & 43 & 29.1 & 157 & 45 & 28.7 \\
\hline & 2 children & & 53 & 35.8 & & 61 & 38.9 \\
\hline
\end{tabular}


Table 1 Baseline characteristics of enrollees in the F3HK intervention trial in four U.S. states, 2016-2017 (Continued)

\begin{tabular}{|c|c|c|c|c|c|c|c|}
\hline & & \multicolumn{3}{|c|}{ Intervention } & \multicolumn{3}{|c|}{ Control } \\
\hline & & $\mathbf{n}$ & Count (Mean) & $\begin{array}{l}\% \\
\text { (SD) }\end{array}$ & $n$ & Count (Mean) & $\begin{array}{l}\% \\
\text { (SD) }\end{array}$ \\
\hline & 3 children & & 30 & 20.3 & & 34 & 21.7 \\
\hline & 4 or more children & & 22 & 14.9 & & 17 & 10.8 \\
\hline \multirow[t]{7}{*}{ Annual household income } & Less than $\$ 9,999$ & 147 & 22 & 15.0 & 155 & 34 & 21.9 \\
\hline & $\$ 10,000-\$ 14,999$ & & 19 & 12.9 & & 11 & 7.1 \\
\hline & $\$ 15,000-\$ 19,999$ & & 16 & 10.9 & & 14 & 9.0 \\
\hline & $\$ 20,000-\$ 24,999$ & & 18 & 12.2 & & 25 & 16.1 \\
\hline & $\$ 25,000-\$ 34,999$ & & 34 & 23.1 & & 28 & 18.1 \\
\hline & $\$ 35,000-\$ 49,999$ & & 31 & 21.1 & & 30 & 19.4 \\
\hline & $\$ 49,999-\$ 74,999$ & & 7 & 4.8 & & 13 & 8.4 \\
\hline \multirow[t]{2}{*}{ Household receive WIC in the past month? } & No & 148 & 87 & 58.8 & 157 & 100 & 63.7 \\
\hline & Yes & & 61 & 41.2 & & 57 & 36.3 \\
\hline \multirow[t]{2}{*}{ Household receive SNAP in the past month? } & No & 147 & 77 & 52.4 & 155 & 74 & 47.7 \\
\hline & Yes & & 70 & 47.6 & & 81 & 52.3 \\
\hline
\end{tabular}

Aforementioned, participants who received monthly SNAP benefits were able to use them to pay for their portion of the CSA share price, and $24 \%$ of participants used SNAP benefits all or most weeks. Of the $62 \%$ who never used SNAP benefits to make a weekly CSA payment, $77 \%$ indicated this was because they did not receive SNAP benefits.

\section{Discussion}

The F3HK trial addressed gaps in our understanding of how CO-CSA affects dietary intake and related practices in low-income households with children, and strengthened the methodology used in examining CSA impacts. Overall, we found that CO-CSA plus nutrition education modestly improved caregivers' FV intake across one season of participation and had no effect on children's FV intake. Almost one-half (47\%) of enrolled children and almost one-third (30\%) of caregivers met FV intake recommendations at baseline; those levels are higher than the U.S. population overall in which less than $10 \%$ of children and adults meet vegetable recommendations, and somewhat more meet fruit recommendations (40\% of children and $12 \%$ of adults) [2, 84]. Enrolled caregivers also were more likely to have a college education or graduate degree than the low-income population overall in the target counties (48.9\% vs 17.8\%) [85]. Given education and the fact that enrolled caregivers had to agree to use their own cash or SNAP benefits to purchase the CO-CSA every week throughout the growing season, the program may have attracted families that were atypical in their orientation toward health. There is other evidence that suggests CO-CSA programs attract a subset of the population, low-income or otherwise, for whom FV access and intake is atypically positive. For example, a descriptive study with low-income families found that CO-CSA members reported significantly higher FV intake for themselves and their children than US averages, and they and their children more often met recommendations for vegetable intake than the overall US population [31]. Two studies reported that households participating in CO-CSA had greater access to or availability of FV at baseline [29, 37]: one of these targeted low-income participants [37] and the other did not [29]. A third study reported that CO-CSA applicants had greater access to and availability of FV relative to a no-CSA comparison sample regardless of whether the applicants actually participated [30]. Although a greater percent of participants in this study met FV guidelines than the general public, the majority of study participants and the general US adult population are not meeting FV intake guidelines [2]. People with lower incomes are even less likely to meet FV recommendations [2]. Future research is needed to determine ways to attract any individuals who are at-risk of low FV intake to CSA, and to make CSA more inclusive and acceptable to households with the greatest financial need.

The sample's atypical baseline FV intake may help to explain why the intervention had no effect on children's FV intake and only a modest effect on caregivers' FV intake, although two-thirds of children and three-quarters of caregivers did not meet FV recommendations at baseline, suggesting that increases in FV intake were still needed to support health. An additional explanation may be that intervention-targeted behaviors may shift first among caregivers, who were more active in intervention activities, and that their behavioral modeling of FV intake and other related outcomes may take longer to manifest in measurable behavior change among their 


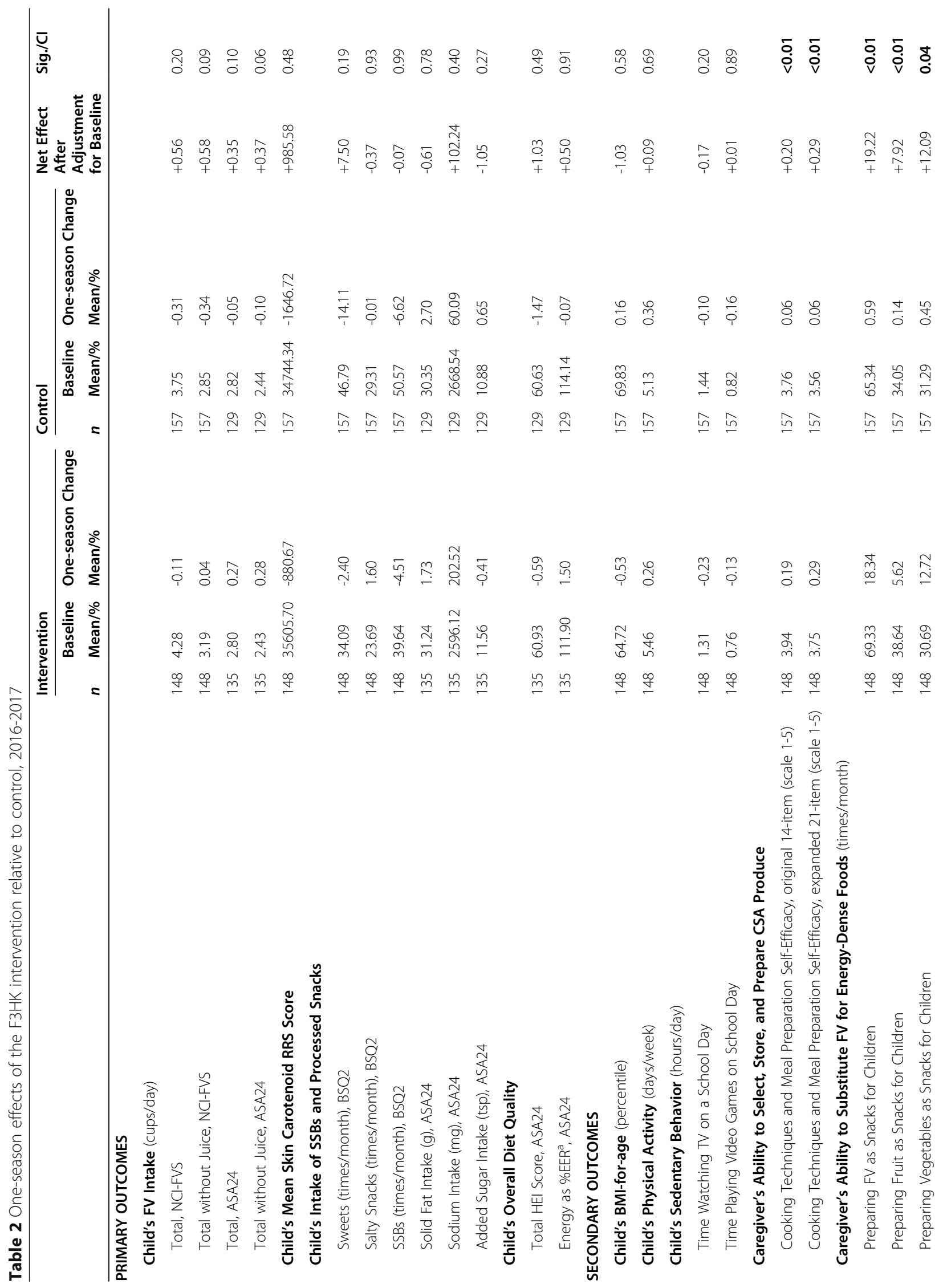




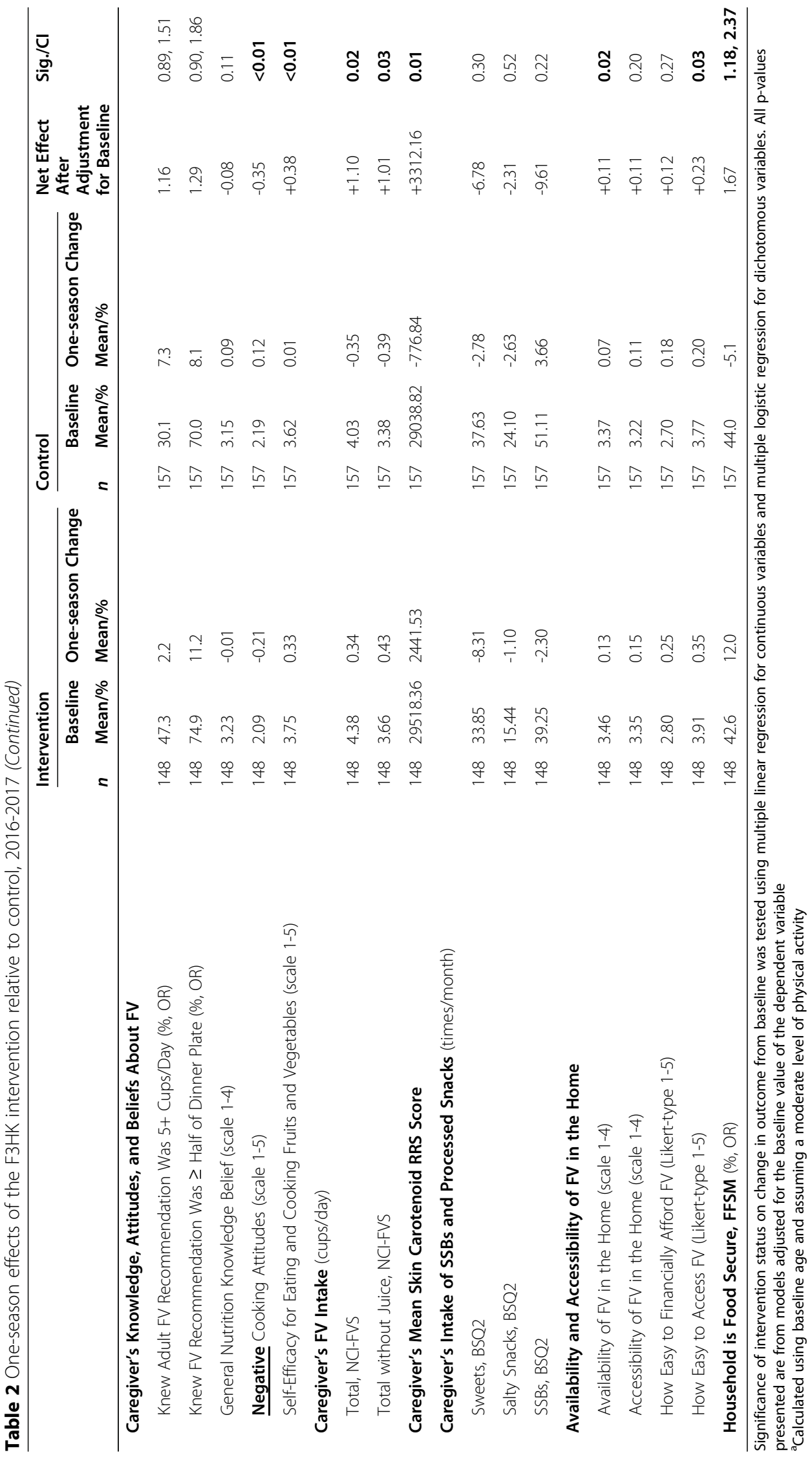




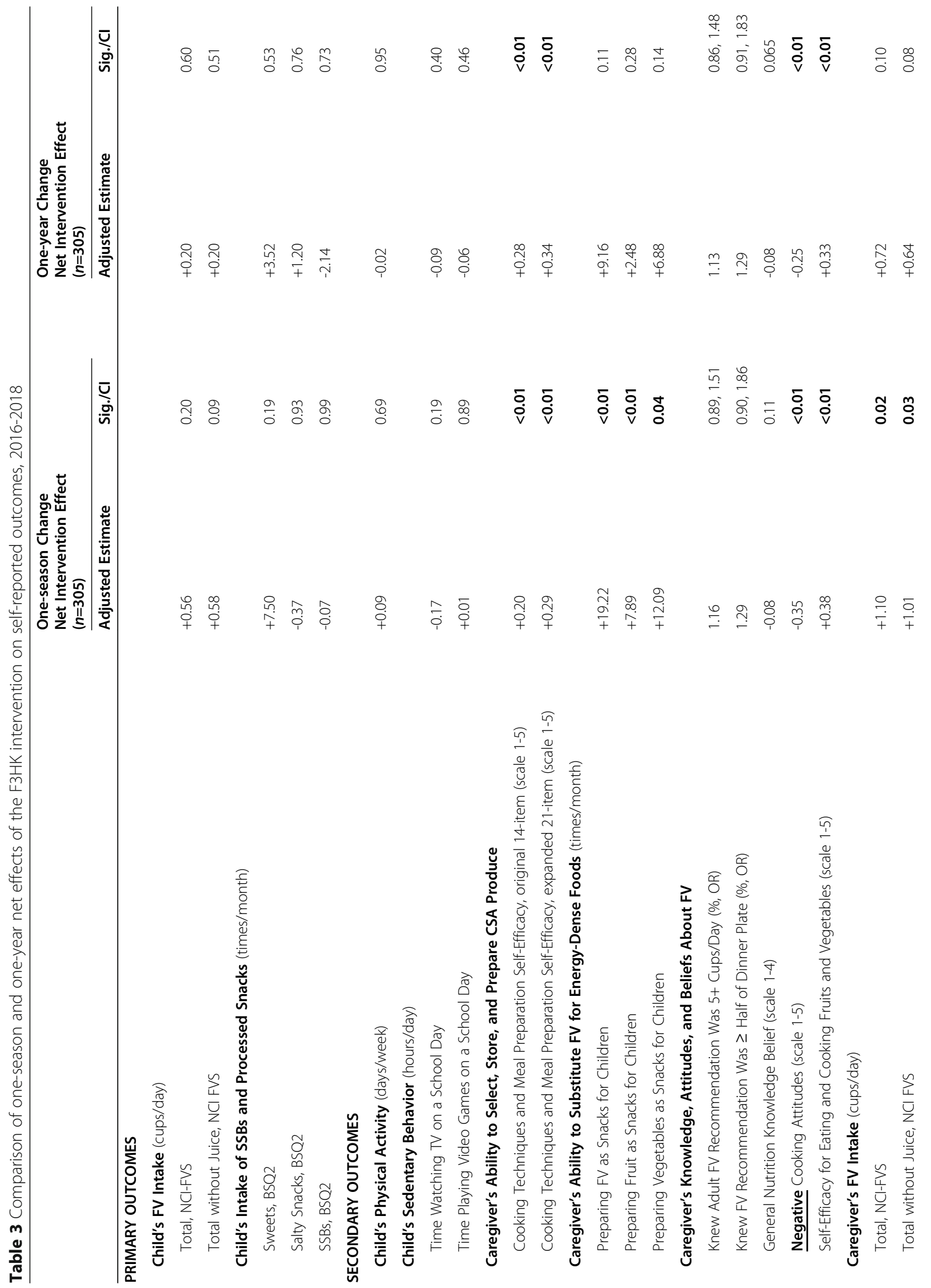




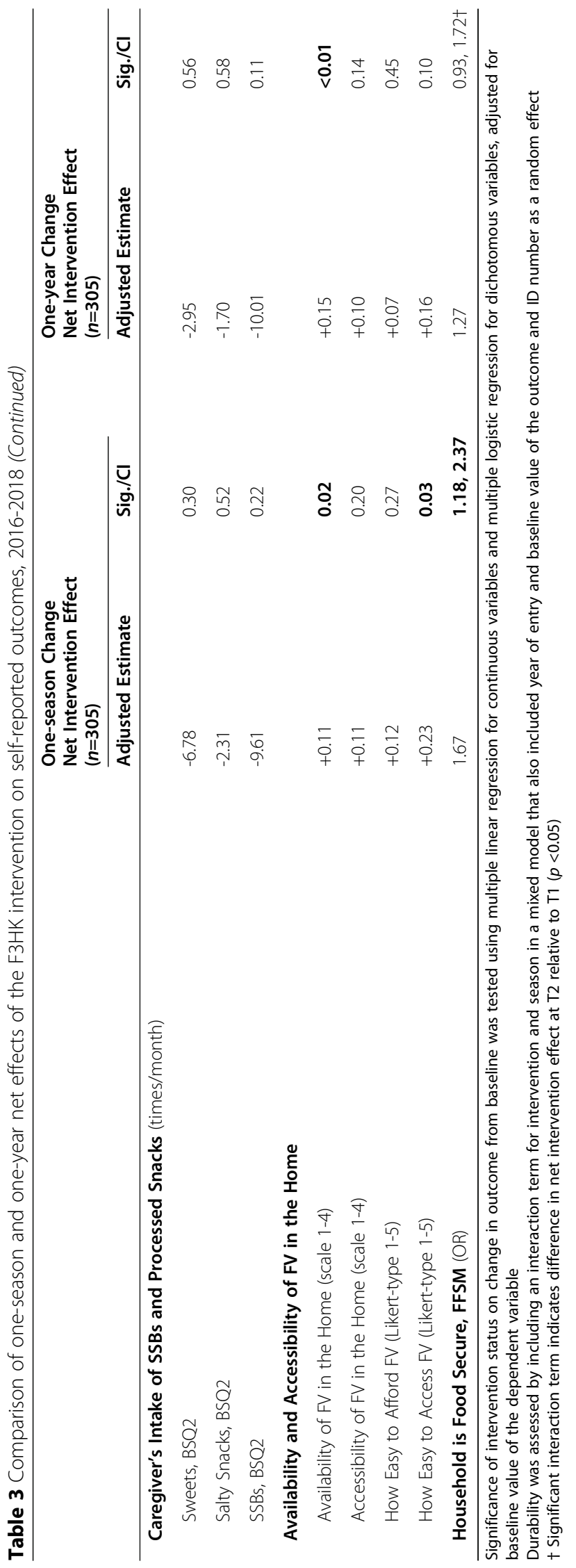


Table 4 Associations between one-season change in outcomes and participation dose among F3HK intervention group members, 2016-2017

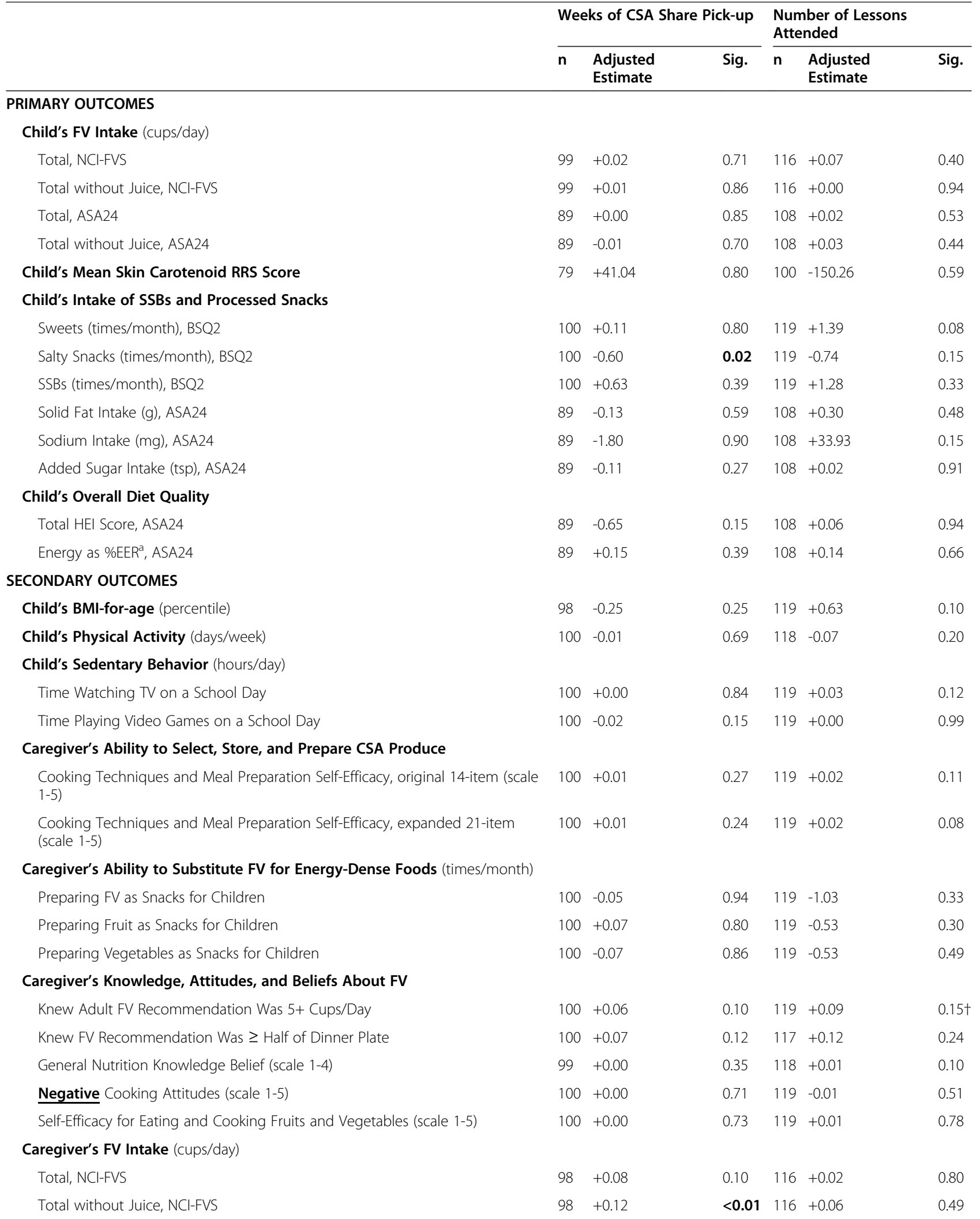


Table 4 Associations between one-season change in outcomes and participation dose among F3HK intervention group members, 2016-2017 (Continued)

\begin{tabular}{|c|c|c|c|c|c|c|}
\hline & \multicolumn{3}{|c|}{ Weeks of CSA Share Pick-up } & \multicolumn{3}{|c|}{$\begin{array}{l}\text { Number of Lessons } \\
\text { Attended }\end{array}$} \\
\hline & $\mathrm{n}$ & $\begin{array}{l}\text { Adjusted } \\
\text { Estimate }\end{array}$ & Sig. & $\mathrm{n}$ & $\begin{array}{l}\text { Adjusted } \\
\text { Estimate }\end{array}$ & Sig. \\
\hline Caregiver's Mean Skin Carotenoid RRS Score & 81 & +287.68 & 0.10 & 102 & -71.16 & 0.81 \\
\hline \multicolumn{7}{|c|}{ Caregiver's Intake of SSBs and Processed Snacks (times/month) } \\
\hline Sweets, BSQ2 & 100 & -0.96 & 0.15 & 118 & -1.42 & 0.23 \\
\hline Salty Snacks, BSQ2 & 100 & -0.02 & 0.94 & 118 & -0.33 & 0.40 \\
\hline SSBs, BSQ2 & 100 & -0.04 & 0.96 & 118 & -0.22 & 0.85 \\
\hline \multicolumn{7}{|l|}{ Availability and Accessibility of FV in the Home } \\
\hline Availability of FV in the Home (scale 1-4) & 99 & +0.00 & 0.56 & 118 & -0.00 & 0.87 \\
\hline Accessibility of FV in the Home (scale 1-4) & 98 & -0.01 & 0.41 & 117 & -0.03 & 0.04 \\
\hline How Easy to Afford FV (Likert-type 1-5) & 100 & +0.02 & 0.07 & 119 & -0.00 & 0.98 \\
\hline How Easy to Access FV (Likert-type 1-5) & 100 & +0.01 & 0.25 & 119 & +0.02 & 0.35 \\
\hline Household is Food Secure, FFSM (In odds) & 99 & +0.09 & 0.04 & 117 & -0.04 & 0.63 \\
\hline
\end{tabular}

Significance of dose effect on change in outcome from baseline was tested using multiple linear regression for continuous variables and multiple logistic regression for dichotomous variables, adjusted for baseline value of the dependent variable

children [86]. This is an important avenue for future research.

F3HK was successful in improving caregivers' cooking attitudes, self-efficacy related to preparing meals and FV specifically, and the frequency with which caregivers prepared FV as snacks for their children. Notably, most of these improvements were maintained into the following spring, well after the summer CSA season had ended. These findings are in contrast with a pilot study $(n=9)$ that found no change in self-efficacy to eat FV or attitudes toward food preparation after CSA participation [29]. The success of the current intervention may be due, in part, to the incorporation of educational materials (available in group classes or online). However, lesson attendance was not found to be associated with positive change in outcomes among the intervention group. Participants were invited, but not required, to attend the nine in-person, CSA-tailored nutrition education classes. Although $77 \%$ of caregivers and $54 \%$ of children attended at least one class [43], overall attendance rates were low. Conversely, the number of weeks that the CSA share was picked-up was associated with a few positive, one-season changes within the intervention group (decrease in child's salty snack intake and increase in adult's FV intake without juice).

F3HK was also successful in improving household food security status, which is notable given that more than half of the families in this study reported food insecurity or participation in a federal food benefit program (WIC and/or SNAP) in the month prior to study enrollment. However, this change was not maintained into the following spring; that is, after the CSA ended, household food security reverted to levels observed before the intervention. This suggests that the modest monetary subsidy for the CSA had a meaningful effect on food security during the active intervention period. Two other studies examined CO-CSA participation in association with food security status; both reported little to no association $[22,27]$.

The present study successfully addressed some of the limitations of prior CO-CSA studies which had small samples [27, 29, 31, 37], no comparison group [27, 29, $31,34]$, included only data from during/after the CSA season [30, 31, 33], and/or recruited samples that did not prioritize low-income participants [33, 34]. F3HK had a sufficiently-powered sample, employed a randomized-controlled trial design with longitudinal data collection, and prioritized recruitment of lowincome families in four geographically distinct parts of the U.S. In addition, we uniquely report on CO-CSA effects on the diet quality of more than one household member. Finally, we included an objective measure of FV intake to support self-reported data.

Despite these strengths, three limitations of this study deserve note. First, low participation in the CSA-tailored education diluted intervention fidelity and may have hindered effectiveness. Second, self-selection into this lengthy intervention trial that required on-going expenditure of cash or benefits resulted in selection bias. As previously mentioned, enrolled caregivers were more educated, and both adults and children had higher than expected FV intake at baseline. Participants were representative of the racial distribution of the communities in which they lived [87] yet were predominantly white. As such, households enrolled in this trial share characteristics with the middle- and upper-income 
households included in most other CSA studies [9-14, $16,17,20,21,23-25,33]$, and may not be generalizable to the population at large. However, the findings are useful for understanding the impact of this intervention on families motivated to commit to a CSA but without the financial resources needed to participate. Third, the net effects of the intervention were estimated largely from self-reported outcome data. Self-reported data, and particularly dietary intake, are prone to recall bias [88, 89] and social desirability bias [90] which may have skewed results. However, positive effects on caregivers' FV intake were corroborated by corresponding effects on their objectively-assessed skin carotenoids thereby reducing concerns about reporting bias.

Rigorously examining participation in CO-CSA plus nutrition education and its impact in real-world settings is timely and necessary given interest in interventions like CO-CSA to address access to healthy foods as a social determinant of health. In a recent survey of Medicaid Medical Director Network members, the most commonly reported screening topics were housing instability and food insecurity [91], suggesting that costeffective and impactful interventions will be needed to address such social determinants of health. Future studies of CO-CSAs should employ pragmatic trials to compare the effectiveness of CO-CSA to other promising interventions for improving FV intake, reducing food insecurity, and addressing health disparities.

\section{Conclusion}

Our study suggests that subsidized CSA memberships plus nutrition education are a viable approach to improve caregiver FV intake, caregiver behaviors and confidence around serving FV, and household food security for lowincome families, although seasonality of most CSAs may limit their potential to improve year-round food security.

\section{Abbreviations}

BMI: Body Mass Index; BSQ2: Beverage and Snack Questionnaire 2; COCSA: Cost-offset Community Supported Agriculture; CSA: Community Supported Agriculture; EER: Estimated Energy Requirements; F3HK: Farm Fresh Foods for Healthy Kids; FCS: Fully conditional specification; FV: Fruit and vegetables; FVS: Fruit and Vegetable Screener; HEI: Healthy Eating Index; ITT: Intent-to-treat; KAB: Knowledge, attitudes, and behaviors; MAR: Missing at random; NCl: National Cancer Institute; RRS: Resonance Raman spectroscopy; SSB: Sugar sweetened beverage

\section{Supplementary Information}

The online version contains supplementary material available at https://doi. org/10.1186/s12966-021-01168-x.

Additional file 1: Supplemental Table 1. One-season net effects of F3HK among enrollees with complete data in four U.S. states, 2016-2017.

\section{Acknowledgments}

The authors wish to express their gratitude to the study participants; CSA farm partners; Leah Volpe, Kristin Bulpitt, Elizabeth Jackson, Jarrod Olsen, Mackenzie McCall, Salem Carriker, and Jared McGuirt for their assistance with data collection; Jen Regan, April Bennett, Ireland Armstrong, Ezra Thomas, Kristin Bulpitt, Salem Carriker, Susan Edwards, Susan Bodette, Kate Bilinski, Melissa Davis, Tara Whitten, and Amber Phillips for tailored education implementation; and Elisabeth Wells, Heather Nedrosik, Bree and Rich Woodbridge, Matthew Glenn, Meredith Leight, Ben Shields and Patricia Parker, Brett Evans, Taylor and Jake Mendel, Andy Jones, Kara Fitzgerald, David Zuckerman, Serena Campbell, Martha Goodlett, and Ann Salafsky for CSA intervention implementation.

\section{Authors' contributions}

RAS conceptualized the research study, oversaw intervention implementation, oversaw collection and analysis of data, wrote sections of the paper, and made final revisions to the manuscript. KLH conceptualized the research study, oversaw intervention implementation and data collection in New York, led data analysis, wrote sections of the paper, and revised the manuscript for important content. SBJP helped conceptualize the study, oversaw intervention implementation and data collection in North Carolina, and revised the manuscript for important content. JK helped conceptualize the study, oversaw intervention implementation and data collection in Vermont, and revised the manuscript for important content. MS helped conceptualize the study, oversaw intervention implementation and data collection in Washington, and revised the manuscript for important content. ASA helped conceptualize the study and revised the manuscript for important content. GAM collected and analyzed data, wrote sections of the paper, and revised the manuscript for important content. EHB contributed to study design, collected data, supported data analysis, and revised the manuscript for important content. JAG drafted the intervention curriculum, collected data, supported data analysis, and revised the manuscript for important content. WW collected data and revised the manuscript for important content. All authors have read and approved the final manuscript.

\section{Funding}

This work was supported by the National Institute of Food and Agriculture, U.S. Department of Agriculture (USDA), under award number 2015-6800123,230 . USDA had no role in the design, analysis, or writing of this article.

\section{Availability of data and materials}

The datasets used and analyzed during the current study are available from the corresponding author on reasonable request.

\section{Declarations}

Ethics approval and consent to participate

The study protocol was approved by University of Vermont and Cornell University Institutional Review Boards (ID numbers: CHRBSS 16-393, 1501005266.) Written informed consent was obtained from all adult participants, and each parent/guardian also provided written permission for their child to participate. Participating children aged 7-12 years provided oral assent.

\section{Consent for publication}

Not applicable.

\section{Competing interests}

The authors declare that they have no competing interests.

\section{Author details}

${ }^{1}$ Texas A\&M AgriLife Research, 600 John Kimbrough Boulevard, Suite 512, College Station, TX 77843, USA. ${ }^{2}$ Department of Population Medicine and Diagnostic Sciences, Master of Public Health Program, Cornell University, S2064 Schurman Hall, Ithaca, NY 14853, USA. ${ }^{3}$ Department of Public Health, East Carolina University, 600 Moye Blvd, Lakeside Annex Modular 7, Greenville, NC 27834, USA. ${ }^{4}$ Department of Community Development and Applied Economics, University of Vermont, 202 Morrill Hall, Burlington, VT 05405, USA. ${ }^{5}$ Ecological Agriculture and Food Systems, The Evergreen State College, 2700 Evergreen Parkway NW, Olympia, WA 98505, USA. ${ }^{6}$ Department of Nutrition, Gillings School of Global Public Health, Center for Health Promotion and Disease Prevention, University of North Carolina at Chapel Hill, 1700 Martin Luther King Boulevard, CB\#7426, Chapel Hill, NC 27599, USA. ${ }^{7}$ Master of Public Health Program, Cornell University, S2074 Schurman Hall, Ithaca, NY 14853, USA. ${ }^{8}$ Department of Nutrition and Food Sciences, 
University of Vermont, 225 B Marsh Life Science, Burlington, VT 05405, USA. ${ }^{9}$ School of Health and Rehabilitation Sciences, College of Medicine, John Glenn College of Public Affairs, The Ohio State University, 210N Page Hall, Columbus, OH 43210, USA. ${ }^{10}$ Center for Rural Studies, University of Vermont, 206 Morrill Hall, 146 University Place, Burlington, VT 05405, USA.

Received: 9 December 2020 Accepted: 5 July 2021

Published online: 31 August 2021

\section{References}

1. Slavin JL, Lloyd B. Health benefits of fruits and vegetables. Adv Nutr. 2012; 3(4):506-16. https://doi.org/10.3945/an.112.002154.

2. Lee-Kwan SH, Moore LV, Blanck HM, Harris DM, Galuska D. Disparities in state-specific adult fruit and vegetable consumption - United States, 2015. Morb Mortal Wkly Rep. 2017;66(45):1241-7. https://doi.org/10.15585/mmwr. mm6645a1.

3. Moore LV, Dodd KW, Thompson FE, Grimm KA, Kim SA, Scanlon KS. Using behavioral risk factor surveillance system data to estimate the percentage of the population meeting US Department of Agriculture food patterns fruit and vegetable intake recommendations. Am J Epidemiol. 2015;181(12):979_ 88. https://doi.org/10.1093/aje/kwu461.

4. Grimm KA, Foltz JL, Blanck HM, Scanlon KS. Household income disparities in fruit and vegetable consumption by state and territory: results of the 2009 behavioral risk factor surveillance system. J Acad Nutr Diet. 2012;112(12): 2014-21. https://doi.org/10.1016/j.jand.2012.08.030

5. Rasmussen M, Krolner R, Klepp K-I, Lytle L, Brug J, Bere E, et al. Determinants of fruit and vegetable consumption among children and adolescents: a review of the literature. Part I: Quantitative studies. Int J Behav Nutr Phys Act. 2006;3(1):1-9.

6. Kamphuis CBM, Giskes K, de Bruijn GJ, Wendel-Vos W, Brug J, van Lenthe FJ. Environmental determinants of fruit and vegetable consumption among adults: a systematic review. Br J Nutr. 2006;96(4):620-35.

7. Calancie L, Leeman J, Pitts SBJ, Khan LK, Fleischhacker S, Evenson KR, et al. Nutrition-related policy and environmental strategies to prevent obesity in rural communities: a systematic review of the literature, 2002-2013. Prev Chronic Dis. 2015;12:140540. https://doi.org/10.5888/pcd12.140540.

8. Khan LK, Sobush K, Keener D, Goodman K, Lowry A, Kakietek J, et al. Recommended community strategies and measurements to prevent obesity in the United States. Morb Mortal Wkly Rep. 2009;58(RR7):1-29.

9. Landis B, Smith TE, Lairson M, Mckay K, Nelson H, O'Briant J. Communitysupported agriculture in the research triangle region of North Carolina: demographics and effects of membership on household food supply and diet. J Hunger Environ Nutr. 2010;5(1):70-84. https://doi.org/10.1080/1932 0240903574403

10. Rossi J, Allen JE, Woods TA, Davis AF. CSA shareholder food lifestyle behaviors: a comparison across consumer groups. Agric Hum Values. 2017; 34(4):855-69. https://doi.org/10.1007/s10460-017-9779-7.

11. Cohen J, Gearhart S, Garland E. Community supported agriculture: a commitment to a healthier diet. J Hunger Environ Nutr. 2012;7(1):20-37. https://doi.org/10.1080/19320248.2012.651393.

12. Hedden JL. The effect of CSA membership on fruit and vegetable intake. Fort Collins: Colorado State University Libraries; 2012.

13. Allen JE, Rossi J, Woods TA, Davis AF. Do community supported agriculture programmes encourage change to food lifestyle behaviours and health outcomes? New evidence from shareholders. Int J Agric Sustain. 2017;15(1): 70-82. https://doi.org/10.1080/14735903.2016.1177866.

14. Curtis KR, Allen K, Ward RA. Food consumption, attitude, and behavioral change among CSA members: a northern Utah case study. J Food Distrib Res. 2015;46(856-2016-58182):3-16.

15. Galt RE, Bradley K, Christensen L, Fake C, Munden-Dixon K, Simpson N, et al. What difference does income make for community supported agriculture (CSA) members in California? Comparing lower-income and higher-income households. Agric Hum Values. 2017;34(2):435-52. https://doi.org/10.1007/s1 0460-016-9724-1

16. Uribe ALM, Winham DM, Wharton CM. Community supported agriculture membership in Arizona. An exploratory study of food and sustainability behaviours. Appetite. 2012;59(2):431-6. https://doi.org/10.1016/j.appet.2012. 06.002 .

17. Arbuckle J. The effect of a fruit and vegetable program on diet quality and produce consumption. Normal: Illinois State University; 2015.
18. Bell ER, Rose M, Roll C, Dupont S. The Good Food Box pilot project as a contribution to addressing food accessibility in the elderly. Can J Diet Pract Res. 2014;75(4):191-4. https://doi.org/10.3148/cjdpr-2014-019.

19. AbuSabha R, Gargin M. Subscription to a fresh produce delivery program increases intake and variety of vegetables at no added cost to customers. J Hunger Environ Nutr. 2019;14(6):796-809

20. Goland C. Community supported agriculture, food consumption patterns, and member commitment. Cult Agric. 2002;24(1):14-25. https://doi.org/10.1 525/cag.2002.24.1.14

21. Vasquez A, Sherwood NE, Larson N, Story M. A novel dietary improvement strategy: examining the potential impact of community-supported agriculture membership. Public Health Nutr. 2016;19(14):2618-28. https:// doi.org/10.1017/S1368980015003638.

22. Miewald C, Holben D, Hall P. Role of a food box program in fruit and vegetable consumption and food security. Can J Diet Pract Res. 2012;73(2): 59-65. https://doi.org/10.3148/73.2.2012.59.

23. Minaker LM, Raine KD, Fisher P, Thompson ME, Van Loon J, Frank LD. Food purchasing from farmers' markets and community-supported agriculture is associated with reduced weight and better diets in a population-based sample. J Hunger Environ Nutr. 2014;9(4):485-97. https://doi.org/10.1080/1 9320248.2014 .898175$.

24. Perez J, Allen P, Brown M. Community supported agriculture on the central coast: the CSA member experience; 2003.

25. Ostrom MR. Toward a community supported agriculture: a case study of resistance and change in the modern food system. Madison: University of Wisconsin; 1997.

26. Guthman J, Morris AW, Allen P. Squaring farm security and food security in two types of alternative food institutions. Rural Sociol. 2006;71(4):662-84. https://doi.org/10.1526/003601106781262034.

27. Andreatta S, Rhyne M, Dery N. Lessons learned from advocating CSAs for low-income and food insecure households. South Rural Sociol. 2008;23(1): 116-48.

28. White MJ, Pitts SBJ, McGuirt JT, Hanson KL, Morgan EH, Kolodinsky J, et al. The perceived influence of cost-offset community-supported agriculture on food access among low-income families. Public Health Nutr. 2018;21(15): 2866-74. https://doi.org/10.1017/S1368980018001751.

29. Izumi BT, Higgins CE, Baron A, Ness SJ, Allan B, Barth ET, et al. Feasibility of using a community-supported agriculture program to increase access to and intake of vegetables among federally qualified health center patients. J Nutr Educ Behav. 2018;50(3):289-296.e1. https://doi.org/10.1016/j.jneb.2017.09.016.

30. Hanson KL, Volpe LC, Kolodinsky J, Hwang G, Wang W, Jilcott Pitts SB, et al. Knowledge, attitudes, beliefs and behaviors regarding fruits and vegetables among cost-offset community-supported agriculture (CSA) applicants, purchasers, and a comparison sample. Nutrients. 2019;11(6):1320. https://doi. org/10.3390/nu11061320.

31. Hanson KL, Kolodinsky J, Wang WW, Morgan EH, Pitts SBJ, Ammerman AS, et al. Adults and children in low-income households that participate in costoffset Community Supported Agriculture have high fruit and vegetable consumption. Nutrients. 2017:9(7):726-35.

32. Johnson DB, Beaudoin S, Smith LT, Beresford SA, LoGerfo JP. Increasing fruit and vegetable intake in homebound elders: the Seattle Senior Farmers' Market Nutrition Pilot Program. Prev Chronic Dis Public Health Res Pract Policy. 2004;1(1):1-9.

33. Rossi JJ, Woods TA, Allen JE. Impacts of a Community Supported Agriculture (CSA) voucher program on food lifestyle behaviors: evidence from an employer-sponsored pilot program. Sustainability. 2017;9(9):1543.

34. Wilkins JL, Farrell TJ, Rangarajan A. Linking vegetable preferences, health and local food systems through community-supported agriculture. Public Health Nutr. 2015;18(13):2392-401. https://doi.org/10.1 017/S1368980015000713.

35. Hoffman JA, Agrawal T, Wirth C, Watts C, Adeduntan G, Myles L, et al. Farm to family: increasing access to affordable fruits and vegetables among urban Head Start families. J Hunger Environ Nutr. 2012;7(2-3):165-77. https://doi.org/10.1080/19320248.2012.703522

36. Berkowitz SA, O'Neill J, Sayer E, Shahid NN, Petrie M, Schouboe S, et al. Health center-based community-supported agriculture: an RCT. Am J Prev Med. 2019;57(6):S55-64. https://doi.org/10.1016/j.amepre.2019.07.015.

37. Quandt SA, Dupuis J, Fish C, D'Agostino RB Jr. Feasibility of using a community-supported agriculture program to improve fruit and vegetable inventories and consumption in an underresourced urban community. Prev Chronic Dis. 2013;10:E136. https://doi.org/10.5888/pcd10.130053 
38. Seguin RA, Morgan EH, Hanson KL, Ammerman AS, Pitts SBJ, Kolodinsky J, et al. Farm Fresh Foods for Healthy Kids (F3HK): an innovative community supported agriculture intervention to prevent childhood obesity in lowincome families and strengthen local agricultural economies. BMC Public Health. 2017;17(1):306. https://doi.org/10.1186/s12889-017-4202-2.

39. Hanson KL, Garner J, Connor LM, Pitts SBJ, McGuirt J, Harris R, et al. Fruit and vegetable preferences and practices may hinder participation in community-supported agriculture among low-income rural families. J Nutr Educ Behav. 2019;51(1):57-67. https://doi.org/10.1016/j.jneb.2018.08.006.

40. McGuirt JT, Pitts SBJ, Hanson KL, DeMarco M, Seguin RA, Kolodinsky J, et al. A modified choice experiment to examine willingness to participate in a community supported agriculture (CSA) program among low-income parents. Renewable Agric Food Syst. 2020;35(2):140-57. https://doi.org/10.1 017/S1742170518000364

41. Morgan EH, Severs MM, Hanson KL, McGuirt J, Becot F, Wang WW, et al. Gaining and maintaining a competitive edge: evidence from CSA members and farmers on local food marketing strategies. Sustainability. 2018;10(7): 2177.

42. Seguin RA, McGuirt JT, Jilcott Pitts SB, Garner J, Hanson KL, Kolodinsky J, et al. Knowledge and experience related to community supported agriculture and local foods among nutrition educators. J Hunger Environ Nutr. 2020;15(2):251-63. https://doi.org/10.1080/19320248.2018.1549520.

43. Garner JA, Jilcott Pitts SB, Hanson KL, Ammerman AS, Kolodinsky J, Sitaker $\mathrm{MH}$, et al. Making community-supported agriculture accessible to lowincome families: findings from the Farm Fresh Foods for Healthy Kids process evaluation. Transl Behav Med. 2020;11(3):754-63.

44. US Department of Agriculture Food and Nutrition Service. Supplemental Nutrition Assistance Program (SNAP): SNAP Eligibility. https://www.fns.usda. gov/snap/recipient/eligibility. Accessed 7 Jun 2021.

45. US Department of Agriculture Food and Nutrition Service. SNAP Data Tables. https://www.fns.usda.gov/pd/supplemental-nutrition-assistanceprogram-snap. Accessed 7 Jun 2021.

46. Bandura A. Self-efficacy: the exercise of control. New York: WH Freeman; 1997.

47. US Department of Health and Human Services USDA. 2015-2020 Dietary Guidelines for Americans. 8th edition. 2015. http://health.gov/dieta ryguidelines/2015/guidelines/. Accessed 13 Oct 2020.

48. U.S. Department of Health and Human Services. Physical Activity Guidelines for Americans. Washington, DC: U.S. Department of Health and Human Services; 2018

49. Pride of New York. From a (pples) to z (ucchini), your guide to New York's produce. https://agriculture.ny.gov/system/files/documents/2019/03/ha rvestchart2016english.pdf. Accessed 13 Oct 2020

50. Washington State Department of Agriculture. Washington grown vegetable seasonality chart https://agr.wa.gov/AglnWA/docs/SeasonalityCha rtHUSSCVegetablefinal.pdf. Accessed 15 Jun 2015.

51. Washington State Department of Agriculture. Washington grown fruits, legume and herbs seasonality chart. https://agr.wa.gov/AglnWA/docs/Sea sonalityChartFruitLegume-Herbsfinal.pdf. Accessed 15 Jun 2015.

52. North Carolina Department of Agriculture \& Consumer Services. What's in season? North Carolina fruit and vegetable availability. http://www.ncagr. gov/markets/availabilitychart.pdf. Accessed 13 Oct 2020.

53. NC State Extension. Specialty crops in North Carolina: acreage and distribution. https://content.ces.ncsu.edu/specialty-cropsin-north-carolina-a creage-and-distribution. Accessed 13 Oct 2020.

54. Vermont.gov. Vermont seasonality calendar. http://agriculture.vermont.gov/ buy_local/harvest_calendar. Accessed 15 Jun 2015.

55. Pomerleau J, Lock K, Knai C, McKee M. Interventions designed to increase adult fruit and vegetable intake can be effective: a systematic review of the literature. J Nutr. 2005;135(10):2486-95. https://doi.org/10.1 093/jn/135.10.2486.

56. Thompson FE, Subar AF, Smith AF, Midthune D, Radimer KL, Kahle LL, et al. Fruit and vegetable assessment: performance of 2 new short instruments and a food frequency questionnaire. J Am Diet Assoc. 2002;102(12):1764-72. https://doi.org/10.1016/S0002-8223(02)90379-2.

57. Neuhouser ML, Lilley S, Lund A, Johnson DB. Development and validation of a beverage and snack questionnaire for use in evaluation of school nutrition policies. J Am Diet Assoc. 2009;109(9):1587-92. https://doi.org/10.1 016/j.jada.2009.06.365.

58. Beverage and Snack Questionnaire 2. http://sharedresources.fredhutch.org/ documents/beverage-and-snack-questionnaire-2. Accessed 13 Oct 2020
59. National Cancer Institute. Automated Self-Administered 24-Hour Recall (ASA24). Bethesda; https://epi.grants.cancer.gov/asa24/.

60. Krebs-Smith SM, Pannucci TE, Subar AF, Kirkpatrick SI, Lerman JL, Tooze JA, et al. Update of the Healthy Eating Index: HEl-2015. J Acad Nutr Diet. 2018; 118(9):1591-602. https://doi.org/10.1016/j.jand.2018.05.021.

61. Kirkpatrick SI, Reedy J, Krebs-Smith SM, Pannucci TE, Subar AF, Wilson MM, et al. Applications of the Healthy Eating Index for surveillance, epidemiology, and intervention research: considerations and caveats. J Acad Nutr Diet. 2018;118(9):1603-21. https://doi.org/10.1016/j.jand.2018.05.020.

62. Aguilar SS, Wengreen HJ, Lefevre M, Madden GJ, Gast J. Skin carotenoids: a biomarker of fruit and vegetable intake in children. J Acad Nutr Diet. 2014; 114(8):1174-80. https://doi.org/10.1016/j.jand.2014.04.026.

63. Scarmo S, Henebery K, Peracchio H, Cartmel B, Lin H, Ermakov IV, et al. Skin carotenoid status measured by resonance Raman spectroscopy as a biomarker of fruit and vegetable intake in preschool children. Eur J Clin Nutr. 2012;66(5):555-60. https://doi.org/10.1038/ejcn.2012.31.

64. Nguyen LM, Scherr RE, Linnell JD, Ermakov IV, Gellermann W, Jahns L, et al. Evaluating the relationship between plasma and skin carotenoids and reported dietary intake in elementary school children to assess fruit and vegetable intake. Arch Biochem Biophys. 2015;572:73-80. https://doi.org/1 0.1016/j.abb.2015.02.015.

65. Aguilar SS, Wengreen HJ, Dew J. Skin carotenoid response to a highcarotenoid juice in children: a randomized clinical trial. J Acad Nutr Diet. 2015;115(11):1771-8. https://doi.org/10.1016/j.jand.2015.06.011.

66. Lohman TG, Roche AF, Martorell R. Anthropometric standardization reference manual. Champaign: Human Kinetics Books; 1988.

67. Kuczmarski RJ, Ogden CL, Guo SS, Grummer-Strawn LM, Flegal KM, Mei Z, et al. 2000 CDC growth charts for the United States: methods and development. Vital Health Stat 11. 2002;(246):1-190.

68. Centers for Disease Control and Prevention. Middle School Youth Risk Behavior Survey. 2015

69. Condrasky MD, Williams JE, Catalano PM, Griffin SF. Development of psychosocial scales for evaluating the impact of a culinary nutrition education program on cooking and healthful eating. J Nutr Educ Behav. 2011;43(6):511-6. https://doi.org/10.1016/j.jneb.2010.09.013.

70. Beydoun MA, Wang YF. Do nutrition knowledge and beliefs modify the association of socio-economic factors and diet quality among US adults? Prev Med. 2008:46(2):145-53. https://doi.org/10.1016/j.ypmed.2007.06.016.

71. Zidichouski JA, Mastaloudis A, Poole SJ, Reading JC, Smidt CR. Clinical validation of a noninvasive, Raman spectroscopic method to assess carotenoid nutritional status in humans. J Am Coll Nutr. 2009;28(6):687-93. https://doi.org/10.1080/07315724.2009.10719802.

72. Jahns L, Johnson LK, Conrad Z, Bukowski M, Raatz SK, Pitts SJ, et al. Concurrent validity of skin carotenoid status as a concentration biomarker of vegetable and fruit intake compared to multiple 24-h recalls and plasma carotenoid concentrations across one year: a cohort study. Nutr J. 2019;18(1):1-8.

73. Mayne ST, Cartmel B, Scarmo S, Lin H, Leffell DJ, Welch E, et al. Noninvasive assessment of dermal carotenoids as a biomarker of fruit and vegetable intake. Am J Clin Nutr. 2010;92(4):794-800. https://doi.org/10.3945/ajcn.2010.29707.

74. Morgan EH, Graham ML, Marshall GA, Hanson KL, Seguin-Fowler RA. Serum carotenoids are strongly associated with dermal carotenoids but not selfreported fruit and vegetable intake among overweight and obese women. Int J Behav Nutr Phys Act. 2019;16(1):104. https://doi.org/10.1186/s12966-01 9-0869-3.

75. Jahns L, Johnson LK, Mayne ST, Cartmel B, Picklo MJ Sr, Ennakov IV, et al. Skin and plasma carotenoid response to a provided intervention diet high in vegetables and fruit: uptake and depletion kinetics. Am J Clin Nutr. 2014; 100(3):930-7. https://doi.org/10.3945/ajcn.114.086900.

76. Robinson-O'Brien R, Neumark-Sztainer D, Hannan PJ, Burgess-Champoux T, Haines J. Fruits and vegetables at home: child and parent perceptions. J Nutr Educ Behav. 2009;41(5):360-4. https://doi.org/10.101 6/j.jneb.2008.08.003.

77. Bickel G, Nord M, Price C, Hamilton W, Cook J. Guide to measuring household food security, revised 2000. Alexandria: U.S. Department of Agriculture, Food and Nutrition Service; 2000.

78. Pedersen AB, Mikkelsen EM, Cronin-Fenton D, Kristensen NR, Pham TM, Pedersen $L$, et al. Missing data and multiple imputation in clinical epidemiological research. Clin Epidemiol. 2017;9:157-66. https://doi.org/1 0.2147/CLEP.S129785.

79. Gullion C, Meltesen G. A method of using multiple imputation in clinical data analysis; 2008. 
80. Newgard CD, Lewis RJ. Missing data: how to best account for what is not known. J Am Med Assoc. 2015;314(9):940-1. https://doi.org/10.1001/jama.2 015.10516 .

81. Huque MH, Carlin JB, Simpson JA, Lee KJ. A comparison of multiple imputation methods for missing data in longitudinal studies. BMC Med Res Methodol. 2018;18(1):168. https://doi.org/10.1186/s12874-018-0615-6.

82. Blimp Software. http://www.appliedmissingdata.com/multilevel-imputation. html. Accessed 13 Oct 2020.

83. Vickers AJ, Altman DG. Analysing controlled trials with baseline and follow up measurements. BMJ. 2001;323(7321):1123-4. https://doi.org/10.1136/ bmj.323.7321.1123.

84. National Cancer Institute. Usual Dietary Intakes: Food Intakes, U.S. Population, 2007-10 2019.

85. US Census Bureau. Table C17003. American Community Survey. Poverty Status in the Past 12 Months. 2017: ACS 1-Year Estimates Detailed Tables.

86. Savage JS, Fisher JO, Birch LL. Parental influence on eating behavior: conception to adolescence. J Law Med Ethics. 2007;35(1):22-34. https://doi. org/10.1111/j.1748-720X.2007.00111.x.

87. Cornell Policy Map, ACS 2014-2018. Philadelphia: https://cornell-policymapcom.proxy.library.cornell.edu/tables. Accessed 13 Oct 2020.

88. Thompson F, Subar A. Dietary assessment methodology. In: Coulston A, Boushey C, Ferruzzi M, editors. Nutrition in the Prevention and Treatment of Disease: Academic Press; 2001.

89. Naska A, Lagiou A, Lagiou P. Dietary assessment methods in epidemiological research: current state of the art and future prospects. F1000Research. 2017:6:926-33.

90. Miller TM, Abdel-Maksoud MF, Crane LA, Marcus AC, Byers TE. Effects of social approval bias on self-reported fruit and vegetable consumption: a randomized controlled trial. Nutr J. 2008;7(1):1-7.

91. Chisolm DJ, Brook DL, Applegate MS, Kelleher KJ. Social determinants of health priorities of state Medicaid programs. BMC Health Serv Res. 2019; 19(1):167. https://doi.org/10.1186/s12913-019-3977-5.

\section{Publisher's Note}

Springer Nature remains neutral with regard to jurisdictional claims in published maps and institutional affiliations.

Ready to submit your research? Choose BMC and benefit from:

- fast, convenient online submission

- thorough peer review by experienced researchers in your field

- rapid publication on acceptance

- support for research data, including large and complex data types

- gold Open Access which fosters wider collaboration and increased citations

- maximum visibility for your research: over $100 \mathrm{M}$ website views per year

At $\mathrm{BMC}$, research is always in progress.

Learn more biomedcentral.com/submissions 